\title{
An Analysis of the Intention of Consumers to Adopt Branded Mobile Applications in South Africa
}

\author{
https://doi.org/10.3991/ijim.v14i04.10602 \\ Pierre Minnaar \\ University of the Witwatersrand, Johannesburg, South Africa \\ Lebogang Mototo \\ University of Cape Town, Cape Town, South Africa \\ Tinashe Chuchu ${ }^{(凶)}$ \\ University of Pretoria, Pretoria, South Africa \\ tinashe.chuchu@up.ac.za
}

\begin{abstract}
The purpose of the study was to conduct an empirical research on adoption of the technology acceptance model on investigating consumers' intention towards the acceptance of branded mobile applications in South Africa. The study was quantitative in nature where 255 participants were utilised for data collection. To analyse the data structural equation modeling approach using SPSS 24 and Amos 24 was conducted. Key findings were that the perceived usefulness of mobile phone applications and their enjoyment had direct and significant impact of consumer attitudes towards the adoption of those mobile applications. The implications of these key findings were that for mobile applications to be adopted in South Africa marketer have to find the best possible ways of making mobile applications user friendly and convenient whether be it for commerce or entertainment purposes.
\end{abstract}

Keywords - Technology, consumers, application, brands, mobile

\section{$1 \quad$ Introduction}

\subsection{Branded mobile applications}

Branded mobile applications provide one of the significant prospects for marketers in terms of reaching prospects that would potential be interested in buying goods or paying for services while engaging with the marketer's brand [1]. Mobile technology provides unlimited access to information and resourceful tools for users [2]. Mobile phone (apps) have generated an increasing fascination among marketers, primarily because of their high capacity for user engagement and the positive impact this presumably has on a user's attitude toward the sponsoring brand [3]. Smartphones and their associated mobile software "applications" or "apps" has become increasingly omni- 
present in daily South Africa. The usage of mobile technology is on an upward trajectory [3]. Mobile applications are not limited to just consumers' intention to adopt them but also the benefits they can receive from this adoption. Therefore, prior research on mobile technologies has focused on mobile learning which greatly relies on user's are willingness adopt a new technology different from the ones that are familiar to the users [4], [5].

There has also been a wide spread transition and evolution from feature phones to smart phones which has shifted the focus in mobile phone products from being "phonecentric' (mobile phones with limited software capabilities) to being "data-centric" (mobile phones with multiple software functionality i.e. global positioning systems (GPS), internet browsing, instant messaging, video calling, picture messaging, games, video and audio playback and editing) [1].

\subsection{Problem statement}

According to a survey done by the Delloitte group, $80 \%$ of branded mobile apps have less than a thousand downloads and $1 \%$ of branded mobile apps have been downloaded more than a million times. Although research done on consumers' intention to adopt smart phone applications exists, not in a South African context, none of them focus on the intention to adopt branded applications [6], [7], [8].

Furthermore, $80 \%$ of branded mobile apps generate less than a thousand downloads, consumers aren't downloading branded apps. In order for companies in South Africa to take full advantage of the benefits of branded apps, they have to convince consumers that branded apps are worth downloading and installing on their smartphones. This paper focused on the factors that influence consumer's intention to adopt branded mobile applications. South Africa offer unique challenges for the implementation of branded apps compared to other countries in the west, Asia and the Americas [6].

\subsection{Purpose of the study}

The purpose of the study was to empirically investigate consumers' acceptance of branded mobile applications.

\subsection{Research question}

To what extent does consumers perceived usefulness, perceived ease of use and perceived enjoyment of branded mobile apps influence their attitude and therefore intention to adopt branded mobile apps?

\subsection{Research objectives}

The research has theoretical and empirical objectives:

- To review literature on marketers, use of branded mobile applications 
- To review literature on how consumers perceived usefulness, perceived ease of use and perceived enjoyment as contributors to their attitude towards branded mobile applications

- To review literature on consumers attitude and intention in adopting smartphone applications.

\subsection{Empirical objectives}

- To investigate how consumers' perceived usefulness influences their attitudes towards adopting branded mobile apps.

- To investigate how consumers' perceived ease of use influences their attitudes towards adopting branded mobile apps.

- To investigate how consumers' perceived ease of use influences their attitudes towards adopting branded mobile apps.

- To investigate how consumers attitude towards branded mobile apps influences their intention to adopt the branded mobile apps.

\section{Literature Review}

\subsection{Previous research}

Previous research makes it clear that branded apps exhibit promising marketing potential and can be an essential element in enhancing a brand experience [9]. Numerous researches have highlighted the potential of using mobile applications in education [10], [11], [12] [13]. The benefits of these applications have heightened expectations from researchers due to their ability to transform the learning process [14]. This study was however concerned with the consumer's acceptance of branded mobile phones. This just makes the case for how popular and versatile mobile technologies have become in human life. In order for companies in South Africa to take full advantage of the benefits of branded apps, they have to convince consumers that branded apps are worth downloading and installing on their smartphones. This paper will focus on the factors that influence consumer's intention to adopt branded mobile applications. South Africa offer unique challenges for the implementation of branded apps compared to other countries in the west, Asia and the Americas [9]. The factors have to be identified and should be considered by marketers not only when designing and developing apps, but especially when promoting branded apps. While lagging behind the West, Asia and the Americas, the number of smartphone users in South Africa is progressively increasing with each passing day [15].

This can be attributable to improved network infrastructure and the decreasing costs of smartphones in South Africa [15]. Unlike more conventional forms of advertising, branded apps are seen as useful to the user [3]. According to [3] some research has been conducted on consumers' intention to adopt smart phone applications although not in a 
South African context, none of them focus on the intention to adopt branded applications. Table 1 presents contemporary and prior research on branded mobile applications.

Table 1. Contemporary and prior research on branded mobile applications

\begin{tabular}{|l|c|}
\hline \multicolumn{1}{|c|}{ Source } & Author(s) \& Year \\
\hline $\begin{array}{l}\text { Beyond the Usefulness of Branded Applications: Insights from Consumer-Brand } \\
\text { Engagement and Self-construal Perspectives. }\end{array}$ & {$[4]$} \\
\hline Designing branded mobile apps: Fundamentals and recommendations. & {$[13]$} \\
\hline $\begin{array}{l}\text { Bon Appétit for apps: young American consumers' acceptance of mobile applica- } \\
\text { tions. }\end{array}$ & {$[13]$} \\
\hline Design patterns for user interface for mobile applications. & {$[10]$} \\
\hline For mobile applications, branding is experience. & {$[10]$} \\
\hline
\end{tabular}

Table 1, presented some of the past literature on branded mobile applications. A central concept that was used to ground the present study, The Technology Acceptance Model is presented in the following section.

\subsection{The technology acceptance model (TAM)}

As organisation are searching for new and innovative ways to communicate with customers, branded mobile apps offer promising marketing potential [3]. As branded mobile apps are still a relatively new way of marketing to South African consumers it is still unclear what factors determine the consumer's willingness to try branded mobile apps. The TAM is a model proposed by concerned with the manner in which users of a system adopt that system. We will apply this model to determine what factors influence South Africa consumer's intention to adopt branded mobile apps.

Among the many variables that cause people to use information technology, two determinants seem to be especially important according to previous research. Firstly, perceived usefulness which states that people tend to use applications to an extent that they believe it will help them perform a certain task better [3]; [8]. Secondly, perceived ease of use states that people might believe that an application is useful but the benefits of usage are outweighed by the effort of use [3]; [8]. In this paper the technology acceptance model has been adapted with perceived enjoyment as was done in a previous surveys and studies [14], [11].

\subsection{Consumers attitude towards adopting branded mobile apps}

Davis hypothesized that the attitude of a user towards a system was a major determent of whether the user will actually use or reject the system [3]. Attitude towards a given behaviour (the adoption of an application) can be defined as a person positive or negative feeling about the actual behaviour [19]. It is shown that general attitudes related to the actual behaviour predict intentions, and intentions predict behaviour. We can conclude that attitude has a direct influence on the consumer's intention to adopt branded mobile applications. 


\subsection{Perceived usefulness}

Perceived usefulness is defined as the degree to which a person believes that using a particular system would enable him or her to do a certain task better. This follows from the word useful, which can be defined as being capable of using something advantageously [16]. Perceived usefulness of a technology measures a user's satisfaction technology [17], [18]. A consumer's perception of how useful an app could be has a substantial influence on the consumer's attitude towards the app. Therefore, unlike traditional methods of advertising, branded mobile apps has to offer the consumer some form of utility, to improve certain task that would most likely be related to a product or service that the brand in question has to offer [3].

\subsection{Perceived ease of use}

Perceived ease of use refers to the extent to which a person believes that using a particular system will be free of any substantial effort [16]. Effort is a finite resource of energy that a person can allocate to the various tasks for which he or she is responsible for [19]. When considering a new technology, a consumer will weigh the cost of the effort against the perceived benefits that he or she will receive by doing so. The perceived ease of use will directly influence consumer's attitudes towards mobile branded mobile apps.

\subsection{Perceived enjoyment}

There are a number of studies that investigates the effects of perceived enjoyment in computer user studies. The original TAM was extended with the construct of perceived enjoyment by [20]. We will also apply this construct to the TAM model to determine South African consumers perceived enjoyment of branded mobile apps. According to previous studies it was concluded that perceived enjoyment of using a mobile service is a more powerful influencer of attitudes and intentions than perceived usefulness [20].

\subsection{Intention to adopt branded mobile apps}

The outcome variable of the model is the consumer's intention to adopt branded mobile apps. The perceptions of the consumer determine their attitude towards branded apps and their attitude in turn determines their intention to adopt the apps, which then leads to the actual use of the app. The intention of all marketers would be to get consumers to this stage of adopting their branded mobile apps. 


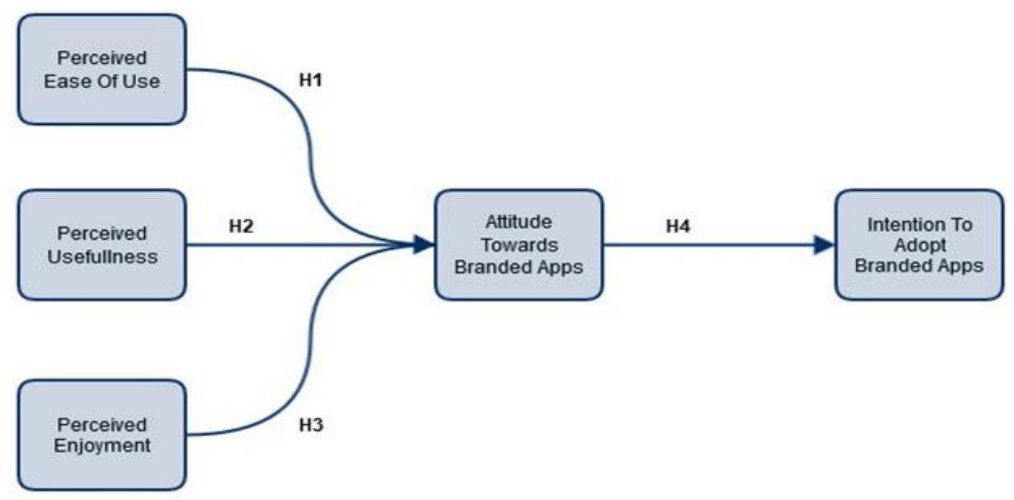

Fig. 1. Proposed conceptual model

\section{Hypothesis statement}

- H1: Consumers perceived usefulness of branded apps has a positive influence on consumer's attitude towards adoption of branded apps.

- H2: Consumers perceived ease of use of branded apps has a positive influence on consumer's attitude towards adoption of branded apps.

- H3: Consumers perceived enjoyment of branded apps has a positive influence on consumer's attitude towards adoption of branded apps.

- H4: Consumers attitude towards branded apps has a positive influence on consumer's intention to adopt branded apps.

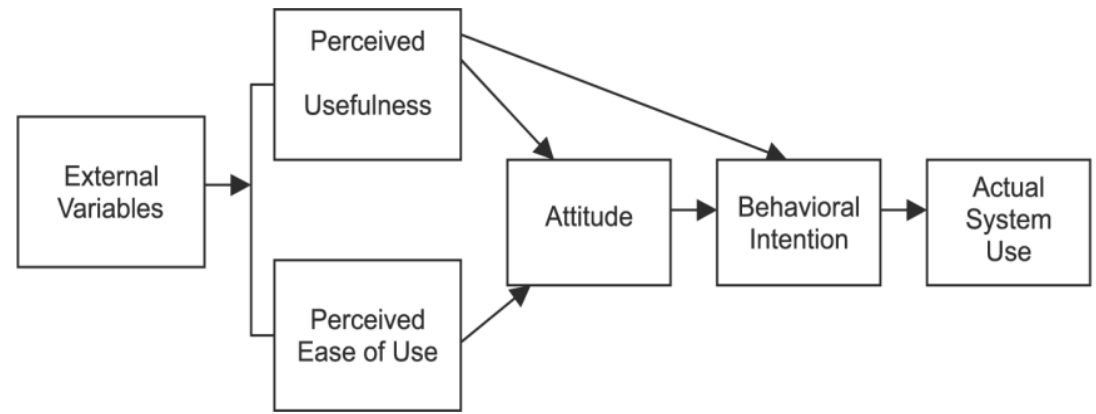

Source: Davis (1989)

Fig. 2. Technology Acceptance Model

The TAM proposes that usage of a specific technology is determined by behavioural intention (BI) [3]. Behavioural intention in the TAM is determined by user's attitude (A) towards using a specific system and its perceived usefulness [3]. [3] Maintain that perceived usefulness and perceived ease of use are the defining factors of attitude, as illustrated in the figure 2 above. The following figure, figure 3 presents the theory of 
reasoned action. Thereafter the technology research methodology for the study is presented.

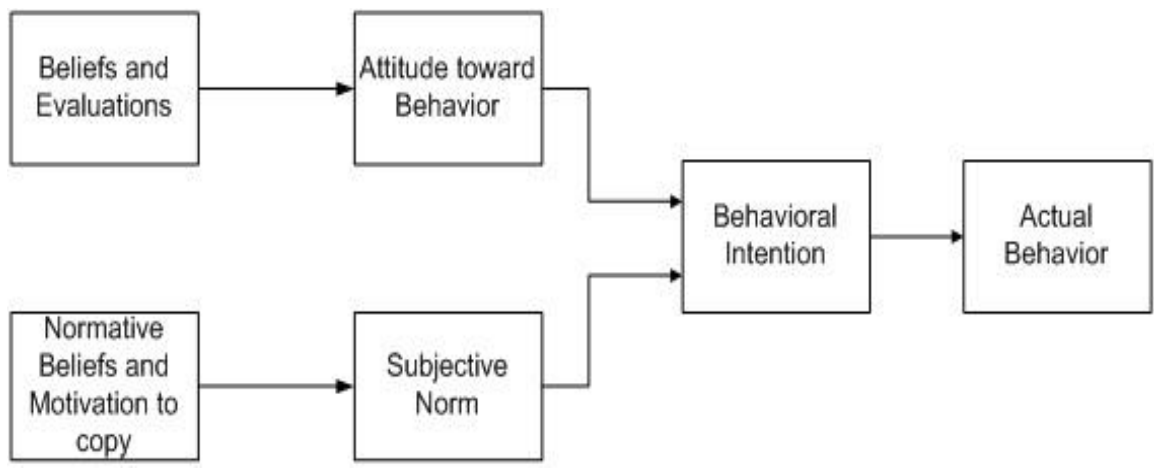

Source: Davis (1989)

Fig. 3. Theory of Reasoned Action Model

\section{Research Method}

The research design presents the sampling method, approach and data collection. As for the research philosophy, a positivist approach was adopted as it was imperative to obtain objective results since the study was quantitative in nature.

\subsection{Sampling method}

A respondent list was be generated by harvesting contact information from the Facebook pages of local South African grocers, Checkers, Pick n Pay and Game. Once this list was generated, consumers were selected through non-probability sampling were an online survey was administered to the willing participants. A total of 300 respondents participated in the study.

\subsection{Data collection}

Measurement items utilised for data collection were adopted from [9] who provided items to measure perceived usefulness and perceived enjoyment. Additionally, perceived ease of use, attitude, behavioural intentions and actual use were measured by items also provided by [8]. Data collection was conducted through means of an online survey. The following section presents the findings of the study.

\subsection{Ethical considerations}

The study was voluntary where respondents were clearly briefed about the intention and purpose of the research. An ethics clearance certificate was obtained from the uni- 
versity responsible for granting research permission. No personal information was collected from participants, hence the study remained anonymous and confidential. Participants were allowed to withdraw from the study at any point and no incentives were provided.

\subsection{Data analysis approach}

In order to analyse the data, the collected data was processed through SPSS 24 and Amos 24 for descriptive statistics and structural equation modeling respectively. In terms of descriptive results, the sample profile (age, education, gender and social class) was generated while structural equation modeling involved measurement model fit assessment and hypothesis testing.

\section{$4 \quad$ Results / Findings}

Table 2. Sample Profile

\begin{tabular}{|c|c|c|c|c|}
\hline & & Frequency & Percentage & Cumulative Percent \\
\hline \multirow[t]{5}{*}{ Age } & $18-23$ years & 77 & 30,2 & 30,2 \\
\hline & $23-30$ years & 114 & 44,7 & 74,9 \\
\hline & $30-40$ years & 38 & 14,9 & 89,8 \\
\hline & $40+$ years & 26 & 10,2 & 100,0 \\
\hline & Total & 255 & 100,0 & \\
\hline \multirow[t]{6}{*}{ Education } & $\begin{array}{l}\text { School-leaving } \\
\text { Certificate }\end{array}$ & 5 & 2,0 & 2,0 \\
\hline & Matric Certificate & 142 & 55,7 & 57,6 \\
\hline & Diploma & 54 & 21,2 & 78,8 \\
\hline & $\begin{array}{l}\text { Undergraduate } \\
\text { Degree }\end{array}$ & 48 & 18,8 & 97,6 \\
\hline & $\begin{array}{l}\text { Post-graduate } \\
\text { Degree }\end{array}$ & 6 & 2,4 & 100,0 \\
\hline & Total & 255 & 100,0 & \\
\hline \multirow[t]{3}{*}{ Gender } & Male & 123 & 48,2 & 48,2 \\
\hline & Female & 132 & 51,8 & 100,0 \\
\hline & Total & 255 & 100,0 & \\
\hline \multirow{5}{*}{$\begin{array}{l}\text { Social } \\
\text { Class }\end{array}$} & Working Class & 81 & 31,8 & 31,8 \\
\hline & Middle Class & 108 & 42,4 & 74,1 \\
\hline & $\begin{array}{l}\text { Upper } \quad \text { Middle } \\
\text { Class }\end{array}$ & 58 & 22,7 & 96,9 \\
\hline & Elite & 8 & 3,1 & 100,0 \\
\hline & Total & 255 & 100,0 & \\
\hline
\end{tabular}

In table 2 it is observed that respondents aged 18 to 23 accounted for more than $30 \%$ of the sample while those aged 23 to 30 represented almost $45 \%$ of the population. In addition (30 to 40 years) and (40 years and more) represented close to $15 \%$ and $10 \%$ respectively. As for education most of the participants stated that their highest qualification was a matric certificate as indicated by 142 out of a total sample of 255 . The lowest representation was that of post-graduate degree holders as they only accounted for about $2 \%$ of the total sample. Males were slightly less than half of the population 
as indicated by $48 \%$ will their female counterparts account for slightly more than half of all the participants as indicated by $51 \%$. Social class was also measured with the middle class being the most prominent category at $42 \%$ of the population while the elite were a mere $3 \%$. The figures that follow present frequency of using branded mobile applications and usage of those applications per week.

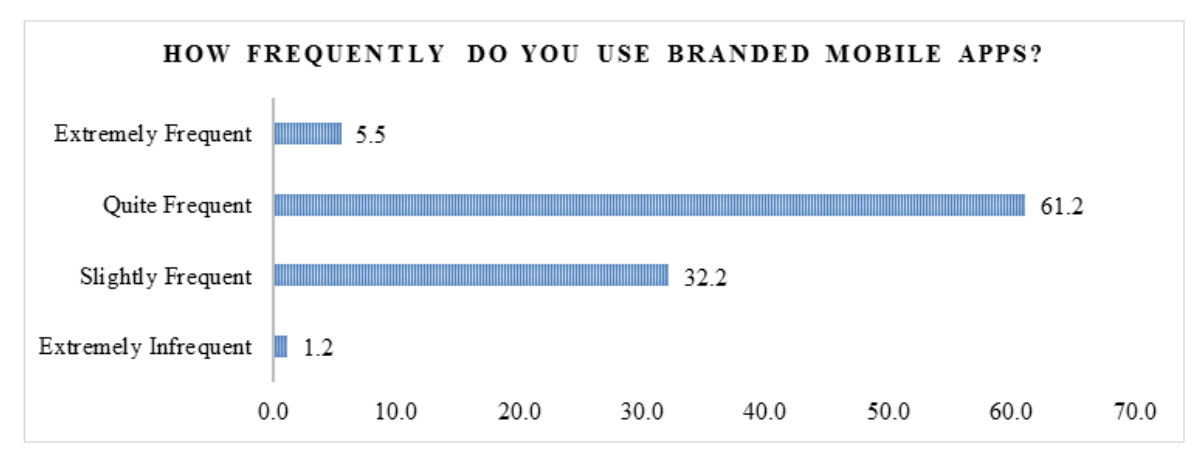

Fig. 4. Frequency of Branded Mobile Applications Usage

As observed in graph, most of the respondents indicated that the use branded mobile applications quite frequently as indicated by $61 \%$ of the entire population. The following table presents the responses concerning the number of times that branded mobile applications are used during a week.

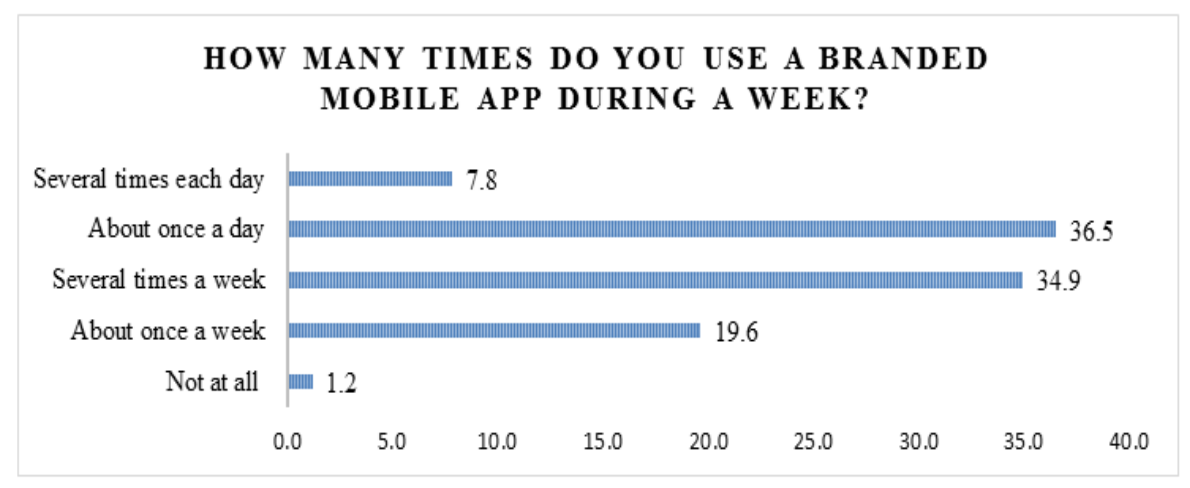

Fig. 5. Usage of Branded mobile Applications in a Week

It is illustrated that the majority of the participants stated that they use branded mobile applications at list once a day indicated by the shown by the $36 \%$ presented in figure 5. This finding was very interesting as it was very similar to those who stated that they use branded mobile application several times a week, which seemed to appear as two contradicting statements. It was also very noticeable that participants who stated that they "do not use branded mobile applications at all" were represented by $1 \%$ of the 
population. The hypotheses stated earlier in the study were empirically tested and the results are presented in the section to follow.

Table 3. Results of Hypothesis Testing

\begin{tabular}{|l|l|c|l|}
\hline \multicolumn{2}{|c|}{ Proposed Hypothesis Relationship } & P-value & \multicolumn{1}{c|}{ Result } \\
\hline Perceived Usefulness (PU) $\rightarrow$ Attitude (A) & $\mathrm{H}_{1}$ & $* * *$ & Supported \& Significant \\
\hline Perceived Enjoyment (PE) $\rightarrow$ Attitude (A) & $\mathrm{H}_{2}$ & $* * *$ & Supported \& Significant \\
\hline Perceived Ese of Use (PEOU) $\rightarrow$ Attitude (A) & $\mathrm{H}_{3}$ & 0.094 & Rejected \& not significant \\
\hline Attitude (A) $\rightarrow$ Behavioural Intention (BI) & $\mathrm{H}_{4}$ & 0.005 & Supported \& Significant \\
\hline
\end{tabular}

$* * *=p$-value not provided but is significant; $\mathrm{p}$ value less than or equal to 0,005 also significant

H1: Perceived usefulness and attitude: The first hypothesis (H1), perceived usefulness and attitude had a p-value of less than 0.01 as demarcated by $* * *$. This relationship was both supported and significant suggesting that the more consumers consider a mobile application useful the more positive their attitudes toward using the application becomes. This finding therefore suggests that's developers of mobile applications ought to provide mobile applications that are viewed as potentially useful in order to influence user-attitudes.

H2: Perceived enjoyment influences attitude: The second hypothesis, (H2), perceived enjoyment and attitude also had a p-value of less than 0.01 as demarcated by ***. This relationship was both supported and significant implying that the more consumers perceived an application to be pleasant to use the more positive their attitudes would turn toward using the application. According to this result, attitudes toward using mobile applications are more favourable when the actual users of the applications find them enjoyable. This therefore means that manufacturers of mobile applications need to invest more in making the applications more entertaining for them to attract more users.

H3: Perceived ease of use influences attitude: The third hypothesis, (H3), perceived ease of use and attitudes had a p-value of 0.094. This hypothesis was not supported and was also rejected. It is important to note that it was the only hypothesis that was rejected. This relationship suggested that perceived ease of use does not necessarily translate to positive attitudes. Possibly reasons for rejection of this hypothesis could be that the perception of a mobile application being user-friendly is not enough to convince users and maybe users need other additional factors to convince them the application can be easily used or adopted.

H4: Attitude influences behavioural intention: The last hypothesis, (H4), established that positive attitudes have a direct and positive influence on behavioural intention. This relationship was both supported and significant at $p<0.01$ as it had a $p$ value of 0.05 . This finding implied that consumers who have favourable attitudes toward the use of mobile applications tend to also have a stronger intention of actually purchasing or paying for that mobile application. Overall, it could be inferred that developers and retailers of mobile applications need to prioritise providing aesthetically pleasing and technically useful applications for them to attract potential users and possibly add to their existing customer base. 


\section{Conclusion and Managerial Implications}

South African consumers seem ready to adopt branded mobile applications. Mostly positive responses indicate that the South African market is ready for more introductions of branded mobile applications. The results of this research paper support the observation that branded mobile applications are believed to be a highly effective marketing tool for companies and brands. The effectiveness and attraction of the branded apps are reliant on the value that it offers. South African consumers aren't willing to download and install an app that purely provides marketing material to them. It is critical that the branded app offers the user some form of utility or entertainment. For the best customer engagement, the value offer by the mobile app should be in line with the company persona and beliefs.

Mobile apps can be combined with company products to provide even more consumer value. The most popular branded app that respondents referred to was the Nike + running app, which combines the attributes identifies for success of a branded app. Marketers should identify what a branded app can offer their company but more importantly, what the app can offer their customers. More resources should be spent on either developing the utility or entertainments aspect of the apps. Actual usage of the respondents indicate that successfully adopted branded apps will be used on a regular basis with more than $90 \%$ of consumers stating that they use their branded apps frequently. This offers brands a new marketing platform that provides continues engagement with their customers.

\section{Research Contribution}

This research provides an analysis of South African consumer's intention to adopt branded mobile apps. This paper reveals that there is a high rate of adoption willingness amongst South African consumers as long as these apps exhibit certain factors such as offering utility value. It therefore also guides marketers and business owners as to what South African consumers want in branded mobile apps before they are willing to adopt. Furthermore, this paper contributes to the currently limited academic literature concerning branded mobile applications, especially in the South African context.

It has already been established that using these applications provides an increase in interests in brands [3]. This study reinforced that finding and added to determining the readiness of South African consumers to accept branded mobile applications. Identifying and researching these variables that influence South African consumers intention to adopt branded apps, can help marketers understand how to effectively design, develop, promote and communicate branded apps which can improve a company's brand and product/service experience delivery. 


\section{$7 \quad$ Further Research}

This research was constrained to the examination of only respondents that have access to a computer. Those individuals that do not own a computer but owns a smartphone was excluded from this study. Given a response rate of less than $60 \%$, time constraints for the completion of the study could not allow for the desired sample size of 350 respondents to be obtained. Additionally, the study was lacking in respondents with rural backgrounds which constitutes a large portion of the South African population. It was also identified that only a small portion of branded apps do become adopted by the majority while other branded apps fail to generate traction. Further research on branded mobile apps may concentrate not only on adoption, but focus more on what makes branded apps successful in the South African context. Further studies may also try and include a broader more comprehensive view by including respondents with more rural backgrounds.

\section{$8 \quad$ References}

[1] Fang, Y. H. (2017). Beyond the Usefulness of Branded Applications: Insights from Consumer-Brand Engagement and Self- construal Perspectives. Psychology \& Marketing, 34(1), 40-58. https://doi.org/10.1002/mar.20972

[2] Papadakis, S., \& Kalogiannakis, M. (2017). Mobile educational applications for children: what educators and parents need to know. International Journal of Mobile Learning and Organisation, 11(3), 256-277. https://doi.org/10.1504/ijmlo.2017.085338

[3] Bellman, S., Potter, R. F., Treleaven-Hassard, S., Robinson, J. A., \& Varan, D. (2011). The effectiveness of branded mobile phone apps. Journal of interactive Marketing, 25(4), 191 200. https://doi.org/10.1016/j.intmar.2011.06.001

[4] Ferreira, J. B., De Freitas, A. S., De Carvalho, M. L. A., De Azevedo, H. C., Gobbo, A. M. C., \& Giovannini, C. J. (2014). Intention to use m-learning in higher education settings. Revista Pretexto, 15(NE), 11-28.

[5] Kalogiannakis, M., \& Papadakis, S. (2019). Evaluating pre-service kindergarten teachers' intention to adopt and use tablets into teaching practice for natural sciences. International Journal of Mobile Learning and Organisation, 13(1), 113-127. https://doi.org/10.1504/ ijmlo.2019.10016617

[6] Hassan, Masoodul, Rehana Kouser, Syed Shafqat Abbas, and Muhammad Azeem (2014), "Consumer Attitudes and Intentions to Adopt Smartphone Apps: Case of Business Students," Pakistan Journal of Commerce and Social Sciences, 8 (3), 763-79.

[7] Rakestraw, T. L., Eunni, R. V., \& Kasuganti, R. R. (2013). The mobile apps industry: A case study. Journal of Business Cases and Applications, 9 (1). 1-26

[8] Yang, H. C. (2013). Bon Appétit for apps: young American consumers' acceptance of mobile applications. Journal of Computer Information Systems, 53(3), 85-96. https://doi.org/ $\underline{10.1080 / 08874417.2013 .11645635}$

[9] Rao, M. (2012). Mobile Africa Report 2011. Sustainable innovation ecosystems. Mobile Monday.

[10] Kalogiannakis, M. and Papadakis, St. (2017a) 'A proposal for teaching ScratchJr programming environment in preservice kindergarten teachers', Proceedings of the 12th Conference of the European Science Education Research Association (ESERA), Research, Practice and 
Collaboration in Science Education, Dublin City University and the University of Limerick, Dublin, Ireland, 21-25 August 2017.

[11] Kalogiannakis, M. and Papadakis, St. (2017b) 'An evaluation of Greek educational android apps for preschoolers', Proceedings of the 12th Conference of the European Science Education Research Association (ESERA), Research, Practice and Collaboration in Science Education, Dublin City University and the University of Limerick, Dublin, Ireland, 21-25 August 2017.

[12] Papadakis, S. (2018). Evaluating pre-service teachers' acceptance of mobile devices with regards to their age and gender: a case study in Greece. International Journal of Mobile Learning and Organisation, 12(4), 336-352. https://doi.org/10.1504/ijmlo.2018.095130

[13] Kim, S., Pyon, T., \& Yoo, S. J. (2017). Does Gender Still Matter? The Usage and Acceptance of Smartphones for Learning in Higher Education. Journal of Learner-Centered Curriculum and Instruction, 17(20), 665-687 https://doi.org/10.22251/jlcci.2017.17.20.665

[14] Kalogiannakis, M., \& Papadakis, S. (2020). The Use of Developmentally Mobile Applications for Preparing Pre-Service Teachers to Promote STEM Activities in Preschool Classrooms. In S. Papadakis, \& M. Kalogiannakis (Eds.), Mobile Learning Applications in Early Childhood Education (pp.82-100). Hershey, PA: IGI Global. doi:10.4018/978-1-7998-14863.ch005 https://doi.org/10.4018/978-1-7998-1486-3.ch005

[15] Kreutzer, T. (2009). Generation mobile: online and digital media usage on mobile phones among low-income urban youth in South Africa. Retrieved on March, 30, 903-920.

[16] Davis, Fred D. (1989), "Perceived Usefulness, Perceived Ease of Use, and User Acceptance of Information Technology," MIS Quarterly, 13 (3), 319-40. https://doi.org/10. $2307 / 249008$

[17] Calisir, F., \& Calisir, F. (2004). The relation of interface usability characteristics, perceived usefulness, and perceived ease of use to end-user satisfaction with enterprise resource planning (ERP) systems. Computers in human behavior, 20(4), 505-515. https://doi. org/10.1016/j.chb.2003.10.004

[18] Chuchu, T., \& Ndoro, T. (2019). An Examination of the Determinants of the Adoption of Mobile Applications as Learning Tools for Higher Education Students. International Journal of Interactive Mobile Technologies, 13(3), 53-67 https://doi.org/10.3991/ijim.v13i03. 10195

[19] Lee, Y., Kozar, K. A., \& Larsen, K. R. (2003). The technology acceptance model: Past, present, and future. Communications of the Association for information systems, 12(1), 50. 751-780 https://doi.org/10.17705/1cais.01250

[20] van der Heijden, Hans (2003), "Factors influencing the usage of Websites: The case of a generic portal in The Netherlands," Information \& Management, 40 (6), 541-49. https:// doi.org/10.1016/s0378-7206(02)00079-4

\section{Authors}

Mr Pierre Minnaar is a student in the Marketing Division of School of Economic and Business Sciences at the University of the Witwatersrand.

Ms Lebogang Mototo holds a Master of Commerce in Marketing from the University of the Witwatersrand. Currently she is a Lecturer (Marketing Section) in the School of Management Studies at the University of Cape Town. She has an affinity for mar- 
keting in a digital world. However, her main area of interest is the marriage of marketing and psychology as well as research on cohorts that the dominant discourse keeps on the periphery of marketing communications.

Dr Tinashe Chuchu (Ph.D) is currently a Senior Lecturer in the Department of Marketing Management, which is part of the Faculty of Economic and Management Sciences at the University of Pretoria. He's specialisation is in consumer behaviour. He has published numerous articles in international journals.

Article submitted 2019-04-04. Resubmitted 2020-01-03. Final acceptance 2020-01-03. Final version published as submitted by the authors. 